\title{
Clinical Supervision: A Genius Tool for Teachers' Professional Growth
}

\author{
Azzeddine Bencherab ${ }^{1}$, Ali Al Maskari²
}

\section{ARTICLE INFO}

Article History:

Received05.02.2020

Received in revised form

17.06.2020

Accepted

Available online 01.07.2021

\begin{abstract}
This paper discusses the necessity of implementing instructional supervision in general with a little focus on clinical supervision. While clinical supervision is seen as an important tool to make teachers develop professionally, it cannot fit all teachers. Supervisors and principals insist on taking into account learners' diversity during the teaching learning process, teachers' diversity is most of the time neglected. As a result, other forms of supervision were highlighted in this paper to offer supervisors' options to adopt the approach that fits their supervisees or institutions. Despite differences between supervisory forms in terms of implementation, all forms discussed in this paper contribute to the teachers' growth. The paper was structured in a way that it highlights the role of teachers in taking in charge their own growth by engaging in reflective practices and dispelling the view that the supervisor is the expert.
\end{abstract}

(C)TUARA Journal. All rights reserved

Keywords:

Growth, professional development, reflective practices, teaching quality

\section{INTRODUCTION}

Quality education cannot be attained without the provision of quality teachers. At the beginning of their career and all through, teachers should be assisted develop teaching skills and grow professionally. Students' achievement is closely linked to teachers' performance (Sergiovanni and Starratt, 2007). One way to ensure that teachers are providing effective instruction is to implement effective supervision. Regrettably, of all times, supervision has been equated to inspection, an administrative task that has to be achieved by an authority referred to as "inspector" whose job is to evaluate control teachers' performance. Sergiovanni (1992) stated that "today, supervision as inspection is an artifact of the past, a function that is no longer tenable or prevalent in contemporary education" (p. 204). Sergiovanni (1992) went on stressing that the traditional supervision is carried out in a way that makes teachers feel they are subordinates whose performance has to be examined. Because supervision is part and parcel of the educational system, teachers should be trained so that they develop in their profession. To develop professionally, a teacher centered supervisory approach needs to be adopted by supervisors. Being bottom up, clinical supervision, as opposed to the traditional supervision, incites teachers in getting engaged in reflective teaching practices with the assistance of a supervisor who would adopt the role of a

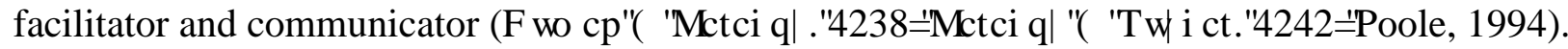
Definitions of supervision

Good (1959) defines supervision as "all efforts directed toward providing leadership to teachers and other educational workers in the improvement of instruction; in the selection and revision of education objectives, materials of instruction, and methods of teaching and the evaluation of instruction" (p 539). Sergiovanni and Starratt (1979), defines clinical supervision as "a face-to face encounter with teachers about teaching, usually in classrooms, with the double-barrelled intent of professional development and improvement of instruction, and with the possibility of making more informal professional decisions/ to solve problems to achieve higher quality of learning" (p. 305). Beach and Reinhartz (2000) regarded instructional supervision as a process that focuses on instruction and provides teachers with information about their teaching so as to develop instructional skills to improve performance.

History of clinical supervision:

The roots of clinical supervision go back to 1950s when Morris Cogan, the pioneer of supervision, realized and admitted that his and associates' teaching practicing were not effective though most of their student teachers were talented. Indeed, Cogan's students confessed that they were entirely dissatisfied with their supervisors' work and that they were not appropriately trained to become effective teachers. Faced with this state of affairs, Cogan and his associates felt the dire need to improve their teaching strategies by teaming up with students. They started, then to work for long hours planning, observing and analyzing. They ensured

${ }^{1}$ azzeddineb@hotmail.fr, Mustapha Stambouli University, Mascara, Algeria, orcid.org/0000-0002-1039-4512

2 alliloub@gmail.com, ADNOC Technical Institute, Abu Dhabi, UAE, orcid.org/0000-0002-9507-9465 
that every observed class was subject to investigation by taking notes of every verbal and nonverbal interaction between the observed teacher and his learners. Post conferences were scheduled after each observed lesson with the purpose of studying and discussing the classroom's events. Indeed, these post conferences yielded positive results and all parties (students and teachers) felt satisfied with the new approach in terms of classroom behaviors analysis as both parties began to ask about the connections between the teacher's objectives, his behavior, the learners' behavior, and the relations of all these with learners' learning. By this approach, future teachers were engaged in the practice of enquiry wherein every event was subject to examination. The process was, then, named clinical supervision because it operated right in the clinic of the classroom wherein every act was observed and discussed. It was built on the principle of relating classroom events during the teaching-learning process and on teacher's interaction with the supervisor to facilitate change and growth (Goldhammer, Anderson \& Karjewski, 1980). Initially, Cogan's model included eight phases which are:

Establishing the teacher-supervision relationship

Planning with the teacher

Planning the strategy of observation

Observing instruction

Analyzing the teaching-learning process

Planning the strategy of the conference

The conference

Renewed planning.

Later, Cogan's model was shrunk to five stages by Mosher and Purpel (1972):

A pre-observation conference between the supervisor and the teacher where an agreement on the framework for the observation session is reached.

A foundation to assist teachers through a classroom observation is established;

An analysis and strategy session is scheduled by the supervisor to organize his/her data after observed lesson and for the teacher to recall what happened during the lesson.

A post-observation conference takes place to allow the teacher to examine the data analysed by the supervisor and ask for any assistance related to his/her professional growth.

A post conference analysis is organized to reflect on to what extent has the goal of professional development been attained.

A few years later, the model was again reduced by Acheson and Gall (1987) to three phases to become the most widely accepted model (see figure 1):

a. Pre- observation conference:

Together, the teacher and the supervisor meet and decide about data collection strategies as regards to the teacher's and students' behaviour with a focus on the area to be observed. For example, the teacher might request the supervisor to focus on the way s/he uses the board or on the way s/he asks questions. In this way, the supervisor is well aware of the teacher's lesson plan, objectives and areas that need to be addressed prior to getting in class.

\section{b. Observation:}

This stage focuses on the classroom interaction. The supervisor attends the class and gathers the data as agreed on during the pre-observation meeting. The data collection can take the form of notes, tapes, videos. 


\section{c. Post observation conference:}

During this meeting both the teacher and the supervisor discuss the observed class in detail and set up an action plan for improvement. The supervisor should be careful enough not to adopt a non-judgmental approach. The post conference, rich in discussion, should result in a plan for improvement. The post conference is of paramount important as it provides the teacher with objective feedback on the current state of his/her instruction by diagnosing and solve instructional problems

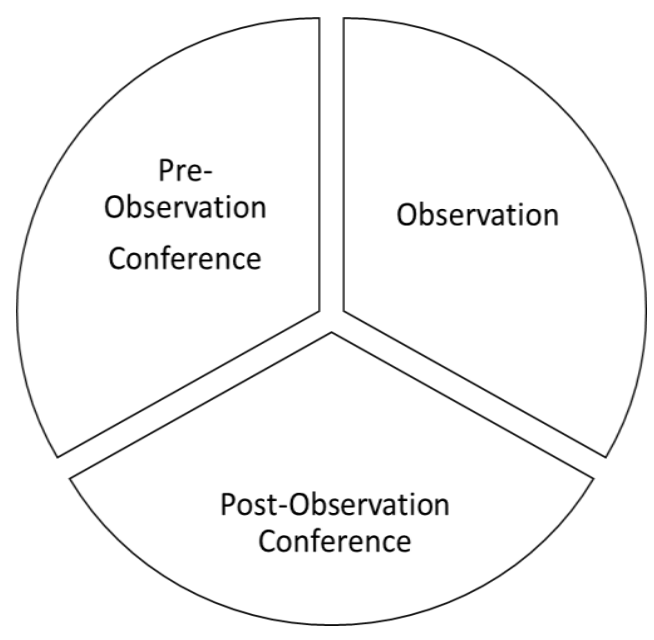

Figure 1. The three- stage cycle

\section{Purposes of Clinical Supervision:}

Supervision is primarily concerned with the improvement of classroom practices which can be achieved by " helping and supporting teachers as they adapt, adopt, and refine the instructional practices they are trying to implement in their classrooms" (As McQuarrie and Wood (1991, p. 93). Because of the dual relationship between teachers' improvement and students' achievement, schools have to provide good education by providing adequate effective supervision. When properly handled, supervision serves several worthy ends, some of which are listed below:

It ensures effective lesson planning and delivery (McQuarrie \& Wood, 1991)

It creates a climate of trust and mutual respect, a willingness to work collaboratively to solve problems, maximizing educational experiences and learning of all students (Nolan \& Hoover, 2004)

It fosters professional growth of teachers (Fullan, 2006)

It provides mechanism for teachers and supervisors to increase their understanding of the teachinglearning process through collective inquiry with other professionals (Nolan \& Francis, 1992).

\section{Characteristics of CS:}

Clinical supervision is featured by several characteristics that makes it different from other types of supervision. Hopkins and Moore (1995) have identified the following characteristics:

It emphasizes teacher's growth instead of teacher defects.

It leads to maximum teachers' growth due to the new supervisor' attitude.

It is regarded as formative as opposed to summative.

Instructional improvement occurs though the systematic interpretation of the data.

It is a teacher-centered process.

The model is ethical, unbiased, and stress free encouraging reflective thinking and teacher independence with more teacher's responsibilities.

\section{Challenges of clinical supervision:}

Supervision demotes inspection and as a result it is always perceived as a stressing experience causing uneasiness and discomfort in the field of education, which according to Hopkins and Moore (1995) engender apprehension. The word "clinical" makes the situation worse as it is equated to a medical issue that needs to be remedied. For Garvie (1990), for clinical supervision to be successful, teachers must be willing to participate in the process and accept the need for improvement of his or her teaching. 
Lovell and Wiles (1983) point out during the clinical supervision process, teachers' individual differences are often ignored since the model is delivered in a inflexible series of steps. Lovell and Wiles (1983) go so far as to assert that teachers cannot go through one model applied to all of them. Teachers require flexibility as regards to their own growth and individual differences must be taken into account. Therefore, other supervisory tools need to be implemented based on their individual differences and needs.

Gordon (1992) believes that clinical supervision has not achieved a wide acceptance because it assumes that the supervisor is fully capable of fulfilling his role. To support his claim, Gordon says that making a contract during the pre-observation conference of what should be addressed does not give room for supervisor to ask further questions. Gordon (1992) such a contract breaks down communication because no probing questions will be asked. In fact, the supervisor will honour his contract by concentrating on the analysis of the agreed upon elements rather than highlighting unsuccessful patterns. Poole (1994) mentions the hierarchal relationship between supervisor and teacher as a serious challenge .Poole (1994) pointed out that the superordinate - subordinate relationship between the supervisor and teacher can make teachers reluctant to disclose their problems to an authority during the process. To dispel any apprehension regarding supervision and make it effective, both parties should cultivate a culture of trust and respect (Cogan, 1973). Failure to develop a collegial attitude between the two parties, the process will degenerate into a superficial, inspection-type supervision exercise" (Symmes, 1998).

\section{Variations of clinical supervision:}

Because clinical supervision cannot be applied to all teachers, supervisors and teachers can adopt other forms of teacher development as recommended by Barber (1990). Some of these forms are discussed below:

Peer coaching: Peer coaching is a model whereby teachers pair up or team up to observe each others' teaching with the purpose of improving instruction (Beach \& Reinhartz, 2000). In the same vein, peer coaching can be defined as "teachers helping each other to reflect on teaching practices and take endeavour to improve one's teaching skills and/or carry out new teaching skills needed to carry out knowledge gained through faculty or curriculum development" (Sullivan and Glanz, 2000, p. 215). What makes it different from other forms of supervision is that the participants in the process are of equal status and are all concerned by bringing innovations in curriculum and development (see figure 2). Its purpose is to learn from each other in order to serve the students effectively as explained by Sergiovanni and Starratt (2007).

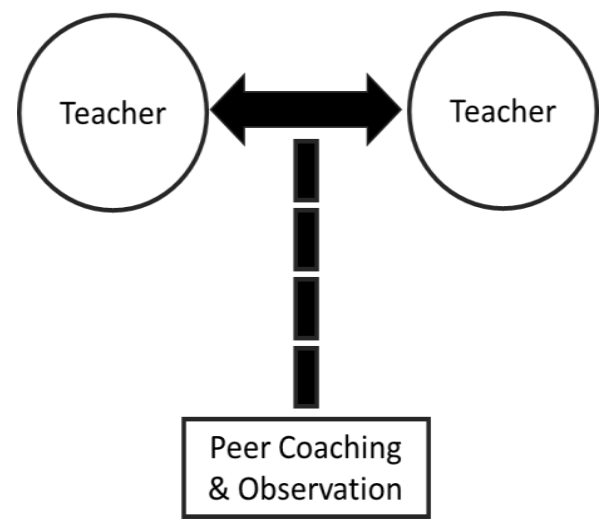

Figure 2. The Peer coaching diagram

Cognitive coaching: The cognitive model raises teachers' awareness about their own teaching effectiveness by involving professionals of different status, novice teachers with experienced teachers for example. The difference in status awards the experienced teacher the role of mediator between the beginner teacher to be coached and his or her own thinking. In other words, cognitive coaching uses strategies to shape and reshape the thinking of the coachee (Costa \& Garmston, 2002). However, it is important that the act of such 
coaching be non- judgmental and that it is expected that the experienced teacher would act as "a facilitator by involving the novice teacher through stimulating questions," (Costa and Garmston,1994, p. 2). The difference between cognitive coaching and peer coaching lies in the fact that cognitive coaching seeks to improve already existing practices. It refers to becoming aware of one's own teaching effectiveness and establishing sound relationships between two or more professionals of different status.

Self- assessment supervision:Self-assessment supervision was coined by Beach \& Reinhartz (2000) while several terms have been used: Self analysis by Schain (1988) and self- help explorative supervision by Gebhard (1990). Sergiovanni \& Starratt (2002) used the terms of self-directed supervision and described it as a process of reflection that engages teachers in a variety of activities (e.g., inventories, reflective journals, and portfolios) for the purpose of instructional improvement by rethinking past instructional episodes and generating alternatives" (Beach \& Reinhartz, 2000, p. 145). The advantage of the self -assessment supervision is that it underlies classroom instruction diagnosis that tends to converge towards reflection that would lead in its turn to try new practices (see figure 3 ).

In this model, responsibility is shifted from supervisors to teachers who are willing to evaluate their classroom instruction by videotaping (Gebbard, 1990); audiotaping or by using live observers (Harris, 1985).

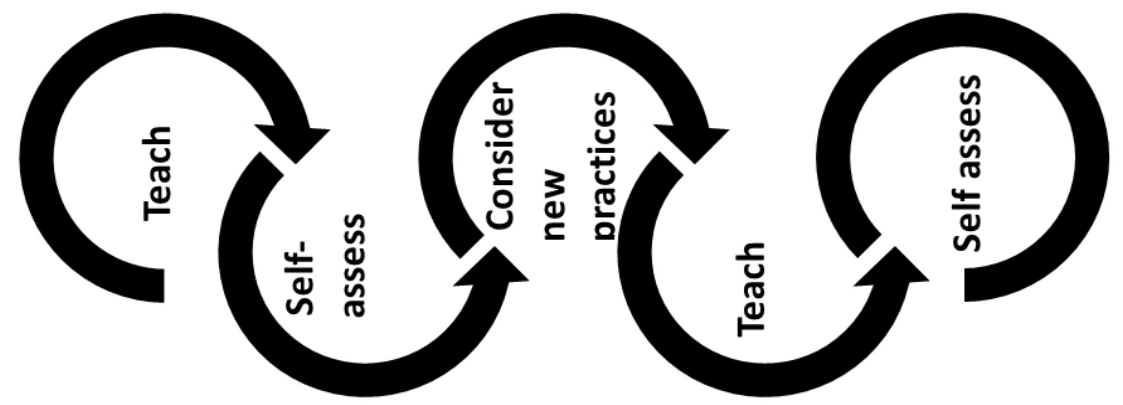

Figure 3. The Peer coaching diagram

\section{Portfolios:}

A teaching portfolio is defined as a process of supervision with compiled collection of artifacts, reproductions, and testimonials that represents the teachers' professional growth and abilities (Riggs \& Sandlin, 2000). A teaching portfolio allows teachers to evaluate themselves and develop their teaching practices provided that it includes not only a collection of the artifacts but a statement of teaching philosophy and a reflective statement. Failure to insert these two documents, the portfolio would be only a photo album.

Pavan Model:

Pavan (1993) updated the clinical supervision model by revising some of the terms and by adding elements of inquiry. Pavan (1993) described the elements of the process of clinical supervision, including planning, observation, analysis, and feedback from the previous works on clinical supervision (see figure 4) and proposed the following:

1. Plan: The lesson is reviewed by the teacher and the observer(s), and a focus is jointly determined during the observation conference.

2. Observe: The data are collected in class according to what has been decided previously.

3. Analyze: The collected data are reviewed and interpreted in relation to the plan, pedagogical theory, and research.

4. Feedback: All collected data and analysis are shared with the teacher so that the lesson dynamics are understood and future plans are made. (p. 136)

Pavan's model suggests that such a process provides professional challenge, professional selfsufficiency in the form of teachers' interaction with administrators, principals, supervisors and colleagues. 


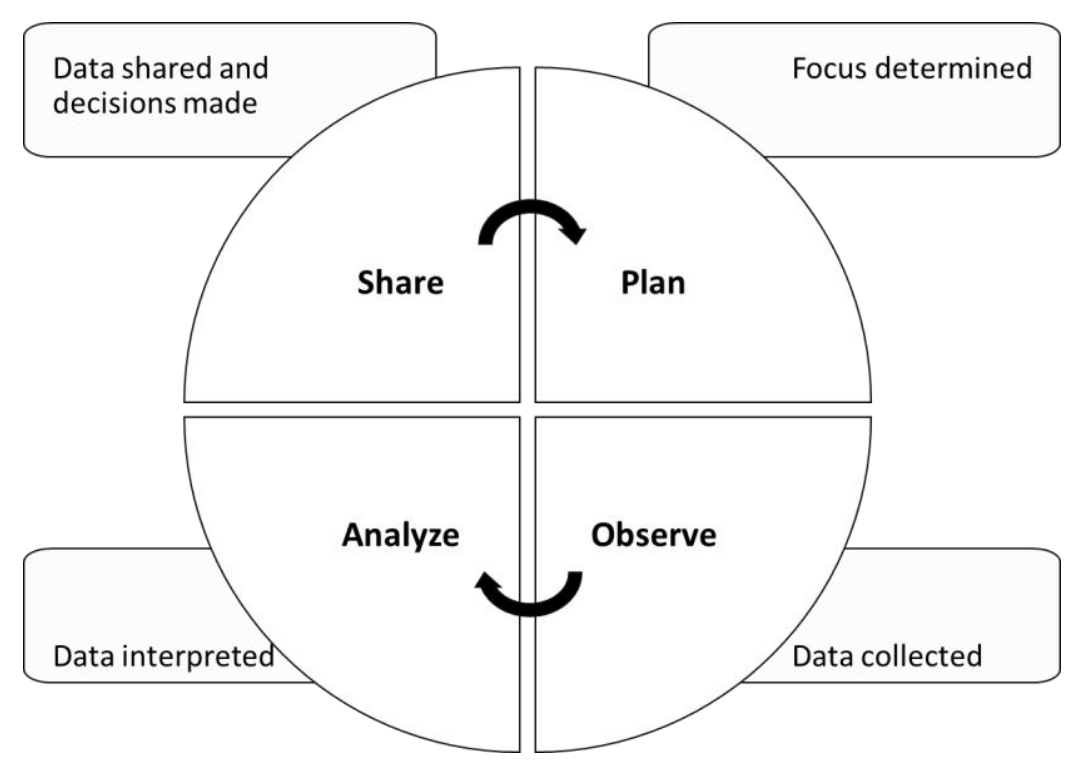

Figure 4. Pavan Model

\section{Conclusion:}

When teachers are supervised through a system of "colleagueship" to use the term of Sergiovanni \& Strarratt (1979) with the purpose of professional development, they become fully engaged in the supervision process (Reiman and Thies-Sprinthall, 1998). Unfortunately, the traditional method of supervision based on three steps: observing, taking notes and writing a report is widely criticized by many teachers as it tends to focus on spotting mistakes and weaknesses rather than helping teachers improve their performance and/or address their weaknesses. Because clinical supervision cannot be applied for all teachers, supervisors or principals that teachers should be supervised according to their needs and their own preferences (Poole, 1994; Renihan, 2002; Sergiovanni \& Starratt, 2007; Zepeda, 2007). Whatever form is used, we believe that despite the differences of each and every approach, they are all built on collegiality, trust, respect and dialogue far from any assumption that the supervisor is the expert.

\section{References:}

Acheson, K. A., \& Gall, M. D. (1987). Techniques in the clinical supervision of teachers: Preservice and inservice applications. White Plains, NY: Longman Inc.

Barber, L. W. (1990). Self-assessment. In J. Millman \& L. Darling-Hammond (Eds.), The new handbook of teacher evaluation: Assessing elementary and secondary school teachers (pp. 216-228). Newbury Park, CA: Sage.

Beach, D. M., \& Reinhartz, J. (2000). Supervisory leadership: Focus on instruction. Boston: Allyn and Bacon.

Cogan, M. L., 1973. Clinical supervision. Boston: Houghton Mifflin.

Costa, A. L., \& Garmston, R. J. (1994). Cognitive coaching: A foundation for renaissance schools. Norwood, MA:

Christophore-Gordon.

Duman,T. \& Karagöz,S. (2016). An evaluation of Turkish teacher education system compared to other models in different countries. International Journal of Educational Research Review,1(1),1-13.

Fullan, M. (2006). Leadership and sustainability, system thinkers in action: Thousand Oaks, CA: Sage Publishers. Nolan, J. F., Jr. (1997). Can a supervisor be a coach? No. In J. Glanz \& R. F. Neville (Eds.), Educational supervision: Perspectives, issues, and controversies (pp. 100-112). Norwood, MA: Christopher-Gordon.

Garvie, N. (1990). Position power and formative supervision. The Canadian School Executive, 10 (5), 23-24.

Gebbard, J. (1990). Models of supervision: Choices. In J. C. Richards \& D. Nunan (Eds.). Second language teacher education (pp. 156-166). Cambridge: Cambridge University Press.

Goldhammer, R., Anderson, R. H, \& Krajewski, R. J. 1980. Clinical supervision: Special methods for the supervision of teachers. $2^{\text {nd }}$ Ed. New York: Holt Rineharlt Winston. 
Good. C. (1959). Dictionary of education. 2nd Ed. New-York: Mc Graw.

Gordon, B. G. (1992). Making clinical supervision a reality: Steps toward implementation. H\&SSP BW, 16(542), 46-5 1.

Harris, B. M. (1975). Supervision behaviour in our education. 2nd Ed. Englewood Cliffs, N. 1. PrenticeHall.

Karagöz,S. \& Rüzgar,M.E. (2020). The observations of student teachers in regard to professional qualifications of advisor teachers during teaching practicum. International Journal of Educational Research Review,5(2),141-150.

McQuarre, F.O.J.,\& Wood, F.H. (1991). Supervision, staff development and evaluation connections. Theory in to Practice, 30, 91-96.

Mosher, R. L., Purpel, D. E. (1972). Supervision: The reluctant profession. Boston: Houghton Mifflin.

Nolan, J., \& Francis, P. (1992). Changing perspectives in curriculum and instruction. In C. D. Glickman (Ed.), Supervision in transition: The 1992 yearbook of the Association for Supervision and Curriculum Development (pp. 44-60). Alexandria, VA: ASCD.

Nolan, J., \& Hoover, L. (2004). Teacher supervision and evaluation. Theory into practice. Hoboken: Wiley \& Jossey-Bass Education.

Pavan, B. N. (1993). Examining clinical supervision practice. R. H. Anderson \& K. J. Snyder (Eds.). Lancaster, PA: Technomic.

Poole, W. L. (1994). Removing the "super" from supervision. Journal of Curriculum and Supervision, 9(3), 284309.

Reiman, A. J., \& Thies-Sprinthall, L. (1998). Mentoring and supervision for teacher development. New York: Longman.

Renihan, P. (2002). Supervision for the improvement of instruction. Saskatoon, SK: University of Saskatchewan.

Riggs, I. M., \& Sandlin, R. A. (2000). Teaching portfolios for support of teachers' professional growth. NASSP Bulletin, 84618), 22-27.

Schain, R. L. (1988). Supervising instruction: What it is $\mathcal{E}$ how to do it. New York: Educators Practical Press.

Sergiovanni, T. J., \& Starrett, R. J. (1979). Supervision: Human Perspectives. 2"nd Ed. NewYork. McGraw-Hill. p.305.

Sergiovanni, T. J. (1992). Moral authority and regeneration of supervision. In C. D. Glickman (Ed.), Supervision in transition: The 1992 year book of the Association for Supervision and Curriculum Development (pp. 203214). Alexandria, VA: ASCD.

Sergiovanni, T. J., \& Starrett, R. J., (2002). Supervision and redefinition. 7th Ed. New York. MC Graw-Hill.

Sergiovanni, T.J. (2006). Principalship: A reflective practice perspective. Boston: Pearson.

Sergiovanni, T. J., \& Starratt, R. J. (2007). Supervision: A redefinition. New York, NY: McGrawHill.

Sullivan, S., \& Glanz, J. (2000). Supervision that improves teaching. Thousand Oaks: Crowin Press.

Symmes, S. C. (1998). Peer clinical supervision and teaching assistants. http://www.msubbillings.edu/modlang/peer.htm

Zepeda, S. (2007). Instructional supervision: Applying tools and concepts (2nd Edn). Larchmont, NY: Eye on Education. 